\title{
Persistent Mobility Deficit in the Absence of Deficits in Activities of Daily Living: A Risk Factor for Mortality
}

\author{
Shafiq R. Khokhar, MD, Yaakov Stern, PhD, Karen Bell, MD, Karen Anderson, MD, Enrique \\ Noe, MD, PhD, Richard Mayeux, MD, MSc, and Steven M. Albert, PhD, MSc
}

OBJECTIVES: To investigate the extent to which selfreported mobility deficit in the absence of impairment in activities of daily living (ADL) is associated with elevated mortality risk.

DESIGN: Prospective cohort study, with annual assessments of mobility and ADL status and ongoing monitoring of vital status.

SETTING: Population-based cohort drawn from Medicare enrollees in New York City.

PARTICIPANTS: One thousand two hundred ninety-eight older adults reporting functional status at baseline (19921994) and 2 years later.

MEASUREMENTS: Subjects reported mobility (e.g., walking, climbing stairs, and rising from a chair) and ADL (e.g., bathing, toilet use, dressing, grooming, and feeding) limitations. Two-year functional status trajectories were noted. We used two additional follow-up periods, at 2 and 4 years, to examine the likelihood that older people with mobility deficit may face an increased risk of death without first passing through a state of enduring ADL disability.

RESULTS: At 2 years, $12.7 \%$ had incident mobility deficit without ADL disability, and $21.3 \%$ were persistently disabled in mobility without ADL disability. Relative to subjects free of disability at baseline and follow-up, risk of mortality in the incident mobility deficit group was elevated at 2 and 4 years but did not achieve statistical significance. By contrast, for subjects with persistent mobility impairment who did not report ADL impairment, the mortality risk was significantly elevated both at 2 years (relative risk $(\mathrm{RR})=2.5 ; 95 \%$ confidence interval $(\mathrm{CI})=$ $1.1-5.7))$ and 4 years $(\mathrm{RR}=2.9 ; 95 \% \mathrm{CI}=1.7-4.9)$ ) of follow-up. Mortality was significantly elevated in this

From the Gertrude H. Sergievsky Center, Department of Neurology, and Taub Institute on Research in Alzheimer's Disease, College of Physicians and Surgeons, Columbia University, New York, New York.

Research supported by NIH (AG 07273) and by the Charles S. Robertson Memorial Gift for Alzheimer's Disease from the Banbury Fund.

Address correspondence to Steven M. Albert, PhD, MSc, Gertrude H. Sergievsky Center, 630 West 168th Street, PH-19, P\&S Box 16, New York, NY 10032. Research supported by NIH (AG07273) and by the Charles S. Robertson Memorial Gift for Alzheimer's Disease from the Banbury Fund. group in analyses restricted to respondents with no or only one comorbid condition.

CONCLUSION: Continuing, self-reported mobility impairment in the absence of ADL deficit is a risk factor for mortality. Older people with self-reported mobility deficit face an increased risk of mortality without first passing through enduring states of ADL disability. J Am Geriatr Soc 49:1539-1543, 2001.

Key words: mobility; activities of daily living; mortality; population-based study

$\mathrm{T}$ he term "mobility" has been used to describe a variety of functional activities, including bed and chair transfer, walking, stair climbing, stooping and kneeling, and getting in and out of cars or buses. The prevalence of mobility deficit varies by setting, although problems with mobility are common. In the Established Populations for Epidemiologic Study of the Elderly (EPESE), about $15 \%$ of the subjects age 65 and older, and $26 \%$ of men and $31 \%$ of women age 85 and older, had difficulty walking. ${ }^{1}$ Eleven percent of subjects age 72 and older in the New Haven, Connecticut, component of the EPESE reported difficulty crossing streets; fewer than $1 \%$ of these pedestrians were able to cross the street in the time allotted at signaled intersections. ${ }^{2}$ Many of the chronic progressive diseases that affect older people, including arthritis, neurological disease, and cardiac and respiratory conditions, have marked effects on mobility. Walking speed also decreases with normal aging, even among patients not labeled as having a "mobility problem." 3

Mobility deficit, as indicated by low scores on lowerextremity performance tests (standing balance, timed walk, chair stands), predicts onset of disability in activities of daily living (ADLs), nursing home admission, and mortality. ${ }^{4}$ Low physical activity has also been associated with an increased risk of mortality ${ }^{5-7}$ and onset of mobility deficit ${ }^{8}$ in a number of prospective studies. Conversely, high levels of physical activity have been shown to predict maintenance of mobility. ${ }^{9}$ Level of physical activity and mobility status ap- 
pear to be partly distinct as predictors of mortality. Hirvensalo et al. have shown that risk of death did not differ by physical activity in older people without mobility impairment. ${ }^{10}$ However, in older people with impaired mobility, higher levels of physical activity reduced the risk of death.

In this research we sought to answer a related question: whether self-reported mobility deficit in the absence of impairment in ADLs is associated with elevated mortality risk. We have not been able to identify studies that have examined this issue directly. Although ADL deficit is usually accompanied by mobility problems, a sizable proportion of older people report deficits in mobility in the absence of ADL disability. Mobility deficit may precede onset of ADL deficit, and older people with mobility impairment may die before reaching enduring states of ADL impairment. We were able to investigate this issue in a prospective study in which a community-based population sample of older adults was assessed at baseline and 2 years later and followed for up to 4 additional years.

\section{METHODS}

\section{Subjects}

Respondents were randomly selected from among Medicare beneficiaries residing in the communities of Washington Heights and Inwood in northern Manhattan, New York City. The sample is tri-ethnic and by design included approximately equal numbers of whites, blacks, and Hispanics. Participants were originally recruited in 19921994. Sampling strata for this survey included age (65-74, $\geq 75$ ) and race/ethnicity (Hispanic, non-Hispanic black, and non-Hispanic white). Thirty-seven systematic replicate subsamples were drawn using random starts, such that each subsample contained age and race/ethnicity groups of equal size. The response rate for the entire sample at baseline was $62 \%$. In addition to cognitive assessment and a social survey, physician examinations were conducted for all patients meeting criteria for dementia and a random subset of nondemented subjects. ${ }^{11}$ In this research, we analyzed the 2- and 4-year mortality experience (1996-1999) of the 1298 respondents who self-reported functional status at baseline (1992-1994) and at the first follow-up, 2 years later (1994-1996).

\section{Assessments}

Assessments were completed in subjects' homes in the majority of cases; otherwise, subjects were seen at Columbia Presbyterian Medical Center. The evaluation process included a 90-minute structured interview regarding sociodemographic information, general health, and self-reported indicators of mobility and ADL status. Interviews were conducted either in English or in Spanish, whichever participants preferred. Information on mortality was obtained from informants at follow-up or from yearly searches of the National Death Index.

We used standard questions regarding mobility and ADL status derived from the Comprehensive Assessment and Referral Evaluation. ${ }^{12}$ The indicators of self-reported mobility were difficulty walking indoors, walking outdoors, climbing stairs, rising from chair, crossing streets, and disembarking from a train or bus. The five indicators of ADL status included difficulty in bathing, toilet use, dressing, grooming, and feeding. Each item was scored dichotomously (none vs any difficulty), and subjects were considered to have mobility or ADL deficit if they reported any difficulty with component items.

For subjects receiving medical evaluations, physicians completed a semistructured medical history from which we constructed a modified Charlson scale for number of comorbidities. ${ }^{13}$ Respondents were scored on the presence of six common medical conditions (myocardial infarction, congestive heart failure, hypertension, diabetes mellitus, dementia, and angina). Physicians also assessed subjects with a modified Barthel index ${ }^{14}$ and a clinician-rated measure of ADL and completed a standardized neurological examination to assess domains relevant for mobility (motor function, sensory function, coordination, movement, gait, reflexes, and tone).

\section{Analyses}

To assess the validity of self-reported mobility status, we computed kappa statistics for self-reports relative to mobility items in the physician-scored Barthel Index and neurological ratings of respondent gait. Kappa is a measure of agreement corrected for the value expected on the basis of chance alone. ${ }^{15}$ Kappa values of .40 to .75 indicate fair to moderate agreement.

The primary goal of this research was to assess whether mobility deficit was associated with an elevated mortality risk in the absence of ADL deficit. To investigate this question, we defined a series of mutually exclusive groups of subjects based on mobility and ADL status at baseline and follow-up 2 years later. Subjects were classified according to self-reports into one of three groups both at baseline and at first follow-up: (1) free of mobility and ADL deficit, (2) mobility deficit only, and (3) both mobility and ADL deficit. We did not define a group characterized by ADL deficit alone because $<1 \%$ of subjects fell into this group. These subjects were combined with subjects who reported both ADL and mobility deficit. We then cross-classified these groups at baseline and follow-up to obtain nine groups representing different functional trajectories. Subjects began follow-up in one of the three states and could remain in that state, improve, or decline over follow-up.

This group status variable was then recoded as a series of dummy variables for logistic regression analyses. In these models, subjects free of ADL and mobility impairment at both time points served as the reference group. The outcome in these analyses was mortality in two periods after the follow-up assessment, 2 and 4 years. Covariates in the models included gender, age, education, and race/ethnicity (with dummy variable coding for non-Hispanic black and Hispanic relative to non-Hispanic white). These models estimate the independent effect of the different functional status trajectories on the risk of death over a relatively short 2-year period and again in a longer 4-year period. To examine the prognostic value of self-reports apart from medical status, we repeated this analysis for the 474 subjects who had medical examinations and no or only one comorbid condition.

Finally, we developed logistic regression models that included both clinician assessment of gait and self-reported mobility status as predictors of mortality. The intent here 
was to determine whether either conveys separate prognostic information, as has been established for self- and clinician ratings of health. ${ }^{16,17}$

\section{RESULTS}

Kappa for agreement between self-reported mobility status and physician rating in the Barthel Index was .44 $(P<$ .001). Kappa for self-reported mobility status and neurological assessment of gait was $.36(P<.001)$. Thus, agreement between self-report and clinician assessment was only fair.

Table 1 presents the distribution of the sample according to functional status trajectory and sociodemographic indices. Of 1,298 subjects completing the two assessments, $30.9 \%$ reported no mobility or ADL problems at either time point. A majority of the sample $(63.6 \%)$ was stable in function $(30.9 \%$ continued to be free of both mobility and ADL deficit, $21.3 \%$ continued to have only mobility deficit, and $11.4 \%$ continued to have both deficits); $12.7 \%$ of subjects had incident mobility impairment without ADL impairment, $21.3 \%$ had continuing mobility impairment in the absence of ADL deficit, and 5.3\% moved from a state of both mobility and ADL impairment to a state of mobility deficit alone. Only $1.5 \%$ made the transition from no deficit to a state of deficit in both mobility and ADL, and only $1.2 \%$ made the reverse transition.

Table 1 also shows that subjects who remained stable or who improved were somewhat younger than subjects who declined. Women were more likely to decline in function than men. Differences by race/ethnicity and education were not prominent.

\section{Mortality by Functional Trajectory}

Table 2 presents mortality by functional trajectory in both the 2-year and 4-year period after the follow-up assessment.

In the adjusted logistic regression model, incident mobility disability without ADL deficit was associated with an elevated mortality risk in both follow-up periods. However, odds ratios (ORs) did not achieve statistical significance $(\mathrm{OR}=1.36 ; 95 \% \mathrm{CI}=0.5-3.8$ at 2 years, $\mathrm{OR}=$ $1.41 ; 95 \% \mathrm{CI}=0.8-2.7$ at 4 years).

By contrast, the odds ratio for persistent mobility disability in the absence of ADL deficit was significantly elevated at both 2 and 4 years. The 2-year OR for mortality was 2.54 $(95 \% \mathrm{CI}=1.1-5.7)$, and the 4 -year OR was $2.91(95 \% \mathrm{CI}=$ 1.7-4.9). The elevated odds ratio at 2 years suggests that these older people were at increased risk of dying without first passing through enduring states of ADL disability.

We repeated the analysis of mortality risk for subjects without major comorbidity, defined as no or only one of the six comorbid conditions recorded by physicians. Results of this analysis, which included 474 respondents, are shown in Table 3.

In this analysis, persistent mobility deficit in the absence of ADL deficit was again a risk factor for mortality, although a significant elevation of risk was evident only in

Table 1. Sociodemographic Characteristics of Groups Defined by Self-Reported Functional Trajectory

\begin{tabular}{|c|c|c|c|c|c|c|c|c|}
\hline \multirow{2}{*}{$\begin{array}{l}\text { Baseline } \\
\text { Status }\end{array}$} & \multirow{2}{*}{$\begin{array}{c}\text { 2-Year Status } \\
\%(n)\end{array}$} & \multirow{2}{*}{$\begin{array}{c}\text { Age }^{*} \\
\text { mean } \pm S D\end{array}$} & \multirow{2}{*}{$\begin{array}{c}\text { Education } \\
\text { years } \pm S D\end{array}$} & \multicolumn{2}{|c|}{ Gender $\%^{\dagger}$} & \multirow{2}{*}{$\begin{array}{l}\text { White } \\
\% \dagger\end{array}$} & \multirow{2}{*}{$\begin{array}{c}\text { Black } \\
\% \dagger\end{array}$} & \multirow{2}{*}{$\begin{array}{c}\text { Hispanic } \\
\% \dagger \ddagger\end{array}$} \\
\hline & & & & Female & Male & & & \\
\hline \multirow[t]{3}{*}{ No deficit } & $\begin{array}{l}\text { No deficit } \\
30.9(402)\end{array}$ & $\begin{array}{l}73.8 \\
(5.0)\end{array}$ & $\begin{array}{c}8.8 \\
(5.1)\end{array}$ & 62.2 & 77.1 & 67.2 & 63.0 & 72.5 \\
\hline & $\begin{array}{l}\text { Mobility deficit } \\
12.7(165)\end{array}$ & $\begin{array}{l}75.2 \\
(6.2)\end{array}$ & $\begin{array}{c}8.7 \\
(4.5)\end{array}$ & 33.3 & 21.3 & 29.6 & 33.1 & 24.6 \\
\hline & $\begin{array}{l}\text { Mobility and } \\
\text { ADL deficit } \\
1.5(19)\end{array}$ & $\begin{array}{l}78.0 \\
(7.3)\end{array}$ & $\begin{array}{l}7.9 \\
(4.2)\end{array}$ & 4.5 & 1.6 & 3.2 & 3.9 & 2.9 \\
\hline \multirow[t]{3}{*}{ Mobility deficit } & $\begin{array}{l}\text { No deficit } \\
\quad 8.8(114)\end{array}$ & $\begin{array}{l}74.5 \\
(5.3)\end{array}$ & $\begin{array}{c}7.9 \\
(4.8)\end{array}$ & 19.9 & 36.7 & 26.4 & 21.3 & 24.8 \\
\hline & $\begin{array}{l}\text { Mobility deficit } \\
21.3(277)\end{array}$ & $\begin{array}{l}75.7 \\
(5.9)\end{array}$ & $\begin{array}{c}8.6 \\
(4.3)\end{array}$ & 61.2 & 45.9 & 59.4 & 58.6 & 55.4 \\
\hline & $\begin{array}{l}\text { Mobility and } \\
\text { ADL deficit } \\
6.9(89)\end{array}$ & $\begin{array}{l}78.2 \\
(7.4)\end{array}$ & $\begin{array}{c}7.6 \\
(4.6)\end{array}$ & 18.9 & 17.4 & 14.2 & 20.1 & 19.8 \\
\hline \multirow[t]{3}{*}{$\begin{array}{l}\text { Mobility and } \\
\text { ADL deficit }\end{array}$} & $\begin{array}{l}\text { No deficit } \\
1.2(15)\end{array}$ & $\begin{array}{l}74.1 \\
(4.5)\end{array}$ & $\begin{array}{c}6.9 \\
(5.6)\end{array}$ & 3.7 & 19.5 & 10.0 & 5.8 & 5.7 \\
\hline & $\begin{array}{l}\text { Mobility deficit } \\
5.3(60)\end{array}$ & $\begin{array}{l}77.0 \\
(6.5)\end{array}$ & $\begin{array}{c}8.4 \\
(5.0)\end{array}$ & 30.4 & 26.8 & 35.0 & 26.7 & 30.2 \\
\hline & $\begin{array}{l}\text { Mobility and } \\
\text { ADL deficit } \\
11.4(148)\end{array}$ & $\begin{array}{l}78.2 \\
(7.2)\end{array}$ & $\begin{array}{c}7.9 \\
(4.1)\end{array}$ & 66.0 & 53.7 & 55.0 & 67.4 & 64.2 \\
\hline Total & $\begin{array}{l}\text { All subjects } \\
100.0(1,298)\end{array}$ & $\begin{array}{l}75.5 \\
(6.1)\end{array}$ & $\begin{array}{c}8.4 \\
(4.7)\end{array}$ & 82.3 & 17.7 & 17.2 & 37.1 & 45.7 \\
\hline
\end{tabular}

\footnotetext{
* Age at study baseline.

† Based on baseline trajectory group as denominator.

₹ Eight subjects with "other" race/ethnicity excluded from race/ethnicity breakdown.

$\mathrm{SD}=$ standard deviation; $\mathrm{ADL}=$ activities of daily living.
} 


\begin{tabular}{|c|c|c|c|c|c|}
\hline Baseline Status & $\begin{array}{c}\text { 2-Year Status } \\
\%(n)\end{array}$ & $\begin{array}{c}\text { 2-Year Mortality } \\
\%(n)\end{array}$ & $\begin{array}{c}\text { 2-Year OR } \\
(95 \% \mathrm{Cl})\end{array}$ & $\begin{array}{c}4-Y e a r \text { Mortality } \\
\%(n)\end{array}$ & $\begin{array}{c}\text { 4-Year OR } \\
(95 \% \mathrm{Cl})\end{array}$ \\
\hline \multirow[t]{3}{*}{ No deficit } & $\begin{array}{l}\text { No deficit } \\
30.9(402)\end{array}$ & $3.0(12)$ & 1.0 (ref) & $8.0(32)$ & 1.0 (ref) \\
\hline & $\begin{array}{l}\text { Mobility deficit } \\
12.7(165)\end{array}$ & $3.6(6)$ & $\begin{array}{c}1.36 \\
(0.5-3.8)\end{array}$ & $10.9(18)$ & $\begin{array}{c}1.41 \\
(0.8-2.7)\end{array}$ \\
\hline & $\begin{array}{l}\text { Mobility and ADL } \\
\text { deficit } \\
1.5 \text { (19) }\end{array}$ & $5.3(1)$ & $\begin{array}{c}2.19 \\
(0.3-18.5)\end{array}$ & $26.3(5)$ & $\begin{array}{c}4.15 \\
(1.3,12.8)\end{array}$ \\
\hline \multirow[t]{3}{*}{ Mobility deficit } & $\begin{array}{l}\text { No deficit } \\
8.8(114)\end{array}$ & $5.3(6)$ & $\begin{array}{c}2.03 \\
(0.7-5.7)\end{array}$ & $12.3(14)$ & $\begin{array}{c}1.7 \\
(0.9-3.4)\end{array}$ \\
\hline & $\begin{array}{c}\text { Mobility deficit } \\
21.3(277)\end{array}$ & $5.4(15)$ & $\begin{array}{c}2.54 \\
(1.1-5.7)\end{array}$ & $17.3(48)$ & $\begin{array}{c}2.91 \\
(1.7-4.9)\end{array}$ \\
\hline & $\begin{array}{l}\text { Mobility and ADL } \\
\text { deficit } \\
6.9 \text { (89) }\end{array}$ & $12.4(11)$ & $\begin{array}{c}5.64 \\
(2.3-14.0)\end{array}$ & $29.2(26)$ & $\begin{array}{c}4.87 \\
(2.6-9.2)\end{array}$ \\
\hline \multirow[t]{3}{*}{ Mobility and ADL deficit } & $\begin{array}{l}\text { No deficit } \\
1.2(15)\end{array}$ & $0(0)$ & undefined & $6.7(1)$ & $\begin{array}{c}0.8 \\
(0.1-6.4)\end{array}$ \\
\hline & $\begin{array}{l}\text { Mobility deficit } \\
5.3(69)\end{array}$ & $5.8(4)$ & $\begin{array}{c}2.72 \\
(0.8-09.0)\end{array}$ & $15.9(11)$ & $\begin{array}{c}2.42 \\
(1.1-5.3)\end{array}$ \\
\hline & $\begin{array}{l}\text { Mobility and ADL } \\
\text { deficit } \\
11.4(148)\end{array}$ & $14.2(21)$ & $\begin{array}{c}6.75 \\
(3.0-15.3)\end{array}$ & $35.8(53)$ & $\begin{array}{c}6.26 \\
(3.6-10.9)\end{array}$ \\
\hline
\end{tabular}

Note: Adjusted for sociodemographic differences (age, gender, education, race/ethnicity); 28 of 1,298 missing data on one or more predictor.

$\mathrm{OR}=$ odds ratio; $\mathrm{CI}=$ confidence interval; $\mathrm{ADL}=$ activities of daily living.

the 4-year follow-up period. The OR at 2 years was 2.02 $(95 \% \mathrm{CI}=0.5-8.2)$ and $2.61(95 \% \mathrm{CI}=1.0-6.6)$ at 4 years. Thus, self-reported mobility deficit was a predictor of mortality even in a group with few or no medical problems.
Finally, we examined the role of physician-assessed gait and self-reported mobility deficit together as predictors of mortality in models that again controlled for sociodemographic differences and ADL status. Using baseline

Table 3. Mortality Risk over 2 and 4 Years by Self-Reported Functional Trajectory: Subjects With No or One Comorbid Condition $(\mathrm{N}=469)$

\begin{tabular}{|c|c|c|c|c|c|}
\hline $\begin{array}{l}\text { Baseline } \\
\text { Status }\end{array}$ & $\begin{array}{c}\text { 2-Year Status } \\
\%(n)\end{array}$ & $\begin{array}{c}\text { 2-Year Mortality } \\
\%(n)\end{array}$ & $\begin{array}{l}2-\text { Year OR } \\
(95 \% \mathrm{Cl})\end{array}$ & $\begin{array}{c}\text { 4-Year } \\
\text { Mortality } \\
\%(n)\end{array}$ & $\begin{array}{c}\text { 4-Year OR } \\
(95 \% \mathrm{Cl})\end{array}$ \\
\hline \multirow[t]{3}{*}{ No deficit } & $\begin{array}{l}\text { No deficit } \\
21.5(101)\end{array}$ & $2.8(4)$ & 1.0 (ref) & $6.3(9)$ & 1.0 (ref) \\
\hline & $\begin{array}{l}\text { Mobility deficit } \\
13.6(64)\end{array}$ & $3.1(2)$ & $\begin{array}{c}1.02 \\
(0.2-5.9)\end{array}$ & $6.3(4)$ & $\begin{array}{c}.82 \\
(0.2-2.9)\end{array}$ \\
\hline & $\begin{array}{l}\text { Mobility and ADL deficit } \\
1.9 \text { (9) }\end{array}$ & 0.0 & undefined & $22.2(2)$ & $\begin{array}{c}5.21 \\
(0.9-31.4)\end{array}$ \\
\hline \multirow[t]{3}{*}{ Mobility deficit } & $\begin{array}{l}\text { No deficit } \\
8.8(52)\end{array}$ & $5.8(3)$ & $\begin{array}{c}2.51 \\
(0.5-12.3)\end{array}$ & $13.5(7)$ & $\begin{array}{l}2.54 \\
(0.9-7.6)\end{array}$ \\
\hline & $\begin{array}{l}\text { Mobility deficit } \\
11.1(98)\end{array}$ & $5.0(5)$ & $\begin{array}{c}2.02 \\
(0.5-8.2)\end{array}$ & $15.0(15)$ & $\begin{array}{c}2.61 \\
(1.0-6.6)\end{array}$ \\
\hline & $\begin{array}{l}\text { Mobility and ADL deficit } \\
4.5 \text { (21) }\end{array}$ & $9.5(2)$ & $\begin{array}{c}3.38 \\
(0.5-21.7)\end{array}$ & $38.1(8)$ & $\begin{array}{c}8.23 \\
(2.5-27.1)\end{array}$ \\
\hline \multirow[t]{3}{*}{$\begin{array}{l}\text { Mobility and ADL } \\
\text { deficit }\end{array}$} & $\begin{array}{l}\text { No deficit } \\
2.1(10)\end{array}$ & 0.0 & undefined & 0.0 & undefined \\
\hline & $\begin{array}{l}\text { Mobility deficit } \\
5.3(25)\end{array}$ & $4.0(1)$ & $\begin{array}{c}1.72 \\
(0.2-17.4)\end{array}$ & $16.0(4)$ & $\begin{array}{c}2.70 \\
(0.7-10.3)\end{array}$ \\
\hline & $\begin{array}{l}\text { Mobility and ADL deficit } \\
10.4 \text { (49) }\end{array}$ & $22.4(11)$ & $\begin{array}{l}10.0 \\
(2.6-38.8)\end{array}$ & $40.8(20)$ & $\begin{array}{c}8.96 \\
(3.3-24.1)\end{array}$ \\
\hline
\end{tabular}

Note: Adjusted for sociodemographic differences (age, gender, education, race-ethnicity); 5 subjects of 474 missing data on one or more predictor.

$\mathrm{OR}=$ odds ratio $; \mathrm{CI}=$ confidence interval $; \mathrm{ADL}=$ activities of daily living. 
assessments, each independently predicted mortality in the subset of subjects without major comorbidity. For example, the OR for the 4-year follow-up was $1.6(95 \% \mathrm{CI}=$ 1.0-2.6) for gait abnormalities and 2.1 (95\% CI $=1.3-$ 3.6) for self-reported mobility problem in the absence of ADL deficit. This finding suggests that self-report and clinician assessment are each an independent source of information relevant for prognosis.

\section{DISCUSSION}

This study has demonstrated that self-reported mobility impairment in the absence of ADL deficit is a risk factor for mortality. Although the incident mobility deficit group did not experience increased mortality beyond levels expected by chance, subjects with continuing mobility deficit in the absence of ADL deficit had an increased risk of mortality. Because the risk of mortality for this group was significantly elevated even 2 years after evaluation, these older people evidently died without first experiencing long periods of ADL disability. For older people with no or little comorbidity, we found a similar pattern.

Agreement between clinician ratings and self-reports of mobility deficit was only fair (with kappa approximately .40), suggesting that respondents based their reports on different kinds of information than did clinicians. For example, clinicians consider speed and turning ability in rating gait, whereas respondents may base ratings on pain or ability to complete tasks. The low kappa suggests that each type of information may have prognostic significance, and, indeed, we found that self- and clinician reports of a mobility problem, apart from ADL, were each independent predictors of mortality. This finding supports research on the independent prognostic value of self- and clinician ratings of health. ${ }^{16,17}$

Based on this research, we suggest that mobility and ADL be considered separate indicators, and that mobilitybased tasks be removed, insofar as possible, from traditional ADL indicators. The original ADL items of Katz ${ }^{18}$ included two mobility items: "transfer" and "going to the toilet." Likewise, the instrumental activities of Lawton and Brody ${ }^{19}$ include a "using transportation" item. Our study shows that many older people only have mobility problems, even over multiple assessments, and that persis- tent mobility deficit in the absence of ADL disability is a risk factor for mortality.

\section{REFERENCES}

1. Coroni-Huntley J, Brock D B, Ostfeld AM et al. Established Populations for Epidemiological Studies of the Elderly. Resource data book (NIH publication No. 86-2443). Hyattsville, MD: National Institutes of Health, 1986.

2. Langlois JA, Keyl PM, Guralnik JM et al. Characteristics of elder pedestrians who have difficulty crossing the street. Am J Public Health 1997;87:393-397.

3. Cohen JJ, Sveen J D, Walker J M et al. Establishing criteria for community ambulation. Top Geriatr Rehab 1987;3:71-77.

4. Guralnik JM, Ferrucci L, Simonsick EM et al. Lower-extremity function in persons over the age of 70 years as a predictor of subsequent disability. New Engl J Med 1995;332:556-561.

5. Harris T, Kovar MG, Suzman R et al. Longitudinal study of physical ability in the oldest-old. Am J Public Health 1989:79;698-702.

6. Rakowski W, Mor V. The association of physical activity and patterns of mortality among older adults in the longitudinal study of aging. 1984-1988 J Gerontol 1992;47:M122-M129.

7. Simonsick EM, Lafferty ME, Phillips CL et al. Risk due to inactivity in physically capable older adults. Am J Public Health 1993;83:1443-1450.

8. Mor V, Murphy J, Masterson-Allen S et al. Risk of functional decline among well elders. J Clin Epidemiol 1989;42:885-890.

9. LaCroix AZ, Guralnik JM, Berkman LF et al. Maintaining mobility in late life. II. Smoking, alcohol consumption, physical activity, and body mass index. Am J Epidemiol 1993;137:858-869.

10. Hirvensalo M, Rantanen T, Heikkinen E. Mobility difficulties and physical activity as predictors of mortality and loss of independence in the community-living older population. J Am Geriatr Soc 2000;48:493-498.

11. Gurland BJ, Wilder DE, Lantigua R et al. Differences in rates of dementia between ethnocultural groups. In: Martin LG, Soldo BJ, eds. Racial and ethnic differences in the health of older Americans. Washington, DC: National Academy Press, 1997, pp 233-269.

12. Gurland BJ, Wilder DE. The CARE interview revisited: Development of an efficient, systematic clinical assessment. J Gerontol 1984;39:129-137.

13. Charlson ME, Pompei P, Ales KL et al. A new method of classifying prognostic morbidity in longitudinal studies: Development and validation. J Chronic Dis 1987;40:373-382.

14. Mahoney Fl, Barthel DW. Functional evaluation: The Barthel index. MD State Med J 1965;14:61-65.

15. Fleiss JL. Statistical Methods for Rates and Proportions. New York: John Wiley \& Sons, 1981.

16. Mossey JM, Shapiro E. Self-rated health-a predictor of mortality among the elderly. Am J Public Health 1982;72:800-808.

17. Idler EL, Kasl S. Health perceptions and survival-do global evaluations of health status really predict mortality? J Gerontol 1991;46:S55-S65.

18. Katz S, Ford AB, Moskowitz RW et al. Studies of illness in the aged. The index of ADL, a standardized measure of sociobiologic function. JAMA 1963; 185:914-919.

19. Lawton MP, Brody EM. Assessment of older people: Self-maintaining and instrumental activities of daily living. Gerontologist 1969;9:179-186. 